\title{
The Phases of Covid-19 Crisis Managment by THE DIRECTORATES OF COMMERCE IN ALGERIA AND ITS EFFECT ON THE CONSUMER BEHAVIOR
}

\author{
SABRI MEKIMAH*
}

\begin{abstract}
This study aims to identify the effect the phases of Covid-19 crisis management by the directorates of commerce in Algeria on the consumer behavior, whereby the descriptive analytical approach has been relied with the use of the form as a main tool for data collection which was distributed to a sample of consumers of 1537 persons. An electronic questionnaire was distributed to them, 1356 analyzable forms were retrieved, with a response rate estimated at $88.22 \%$, to test the study hypotheses, the SPSS statistical program was used, which includes a set of statistical methods to analyze the answers and test the study hypotheses. We reached significant results indicating that the influence of the Covid 19 crisis management by commerce directorates on the Algerian consumer behavior is average. Where $52.7 \%$ of the changes in the level of consumer behavior are caused by the change in the level of control of the stages of Covid 19 crisis management, this requires that the Algerian trade directorates to pay more attention to the strict application of the Covid 19 crisis management phases.
\end{abstract}

Keywords: Crisis Management, Covid-19 Crisis, Consumer Behavior, The directorates of commerce

JEL Classification: $H 55, M 38, I 18$

\section{INTRODUCTION}

The world is now facing an unprecedented situation in terms of continuous challenges and rapid changes that lead to various crises of all types and their effects on countries economically and financially, and its abilities to cope and adapt to the prevailing conditions that may lead to unprecedented disasters.

Particularly, we find the Covid-19 crisis, as an unprecedented global pandemic in modern times, as it includes all the economic, social, psychological and geopolitical angles, it will also be the subject of research, studies and scientific symposiums for research centers and leaders of strategic thinking at the universal

\footnotetext{
*(Corresponding Author), University 20 août 1955, Skikda, Algeria. E-mail: sab88mek@ gmail.com.
} 
level, It particularly affects the economies of countries and their foreign and domestic trade.

Algeria is also one of the countries of the world that was afflicted by this pandemic, it directly and quickly affected its economy and its commercial activity, which will be affected negatively by the quarantine measures, likewise, this pandemic affects also unless, it is controlled and organized well,, this leads to the epidemic more and more. That is why the government is trying, through the Ministry of Commerce and its directorates spread across the country, to adopt scientific and practical ideas in crisis management. Considering the latter as decisions making body and setting the appropriate decision for every executive work, so that commerce directorates will be able to deal with this crisis that it is going through, under these environmental and health conditions, it must have well-defined strategies that help it to manage the crisis successfully. It is affected by numerous factors, which makes it an accurate topic that many researchers have dealt with in various fields. The consumer also has a behavior characterized by a lot of complexity, which led to the diversity of theories that knew it and the factors affected by it directly or indirectly. It is therefore considered one of the difficult, complex, and vital tasks that confront Algeria in general, as it did not receive a sufficient attention until late in comparison to studies related to the human behavior of the individual which needs a lot of development and study.

From the foregoing, the present study aims to reach to know the effect of the management of the Covid-19 crisis by the Directorate of Commerce in Algeria on consumer behavior, we can systematically present the problematic of the study as follows:

$\circ$ To what extent do the phases of Covid-19 crisis management by the directorates of commerce in Algeria affect consumer behavior?

- To clarify the subject of the study more, we ask the following questions:

- To what extent does the avoidance phase of Covid-19 crisis by the commerce directorates affect the behavior of the Algerian consumer?

- To what extant does the preparation and the recognition of the existence phase of Covid 19 crisis by the commerce directorates affect the behavior of the Algerian consumer?

- To what extant does the containment and settlement phase of Covid 19 crisis by commerce directorates affect the behavior of the Algerian consumer?

- To what extant does the benefiting phase of Covid 19 crisis by commerce directorates affect the behavior of the Algerian consumer? 
The importance of the study is that the concept of crises, particularly Covid 19 crisis, has become a widespread concept in our contemporary societies, but more complex in its application. As crises afflict a person with different demographic diversity, this requires the need for constant readiness to address them, due to the concern of the importance of the Algerian consumer behavior which is staying safe and sound.

The research aims to achieve the following objectives:

o The clarification of the most important concepts related to crisis management and consumer purchasing behavior.

- Highlight the effect of Covid 19 crisis management phases by commerce directorates on the Algerian consumer purchasing behavior.

There are many previous studies that are related to the subject of this research, especially studies that combine crisis management and consumer behavior, as well as studies that address the effects of the Covid crisis-19, the most important and most recent of the following studies:

- Study entitled: Consumers behavior in crisis situations. Research on the effects of covid-19 in Romania.

The article aims at analyzing the behavior of the Romanian consumer in the context of Covid 19 emergence, The performed research has highlighted the particularities of the emergence of this sanitary crisis at the local economy level. Although the Romanian population's infection degree has been more, advocate of traditional commerce, has been forced to appeal to modern trade methods based on online shopping, and provide the maintenance of the trade behavior. (stanciu \& others, 2020)

- Study entitled: The influence of crisis management on customer purchase intention, International conference on business sustainability and innovation.

The purpose of this paper is to review about the influence of crisis management on customer purchase, The number of product-harm crisis in Malaysia in the present market is rising due to factors like the increasingly complex products, An organization should prepare with operative and effective crisis management and crisis communication plans that can support their execution of crisis management (Shaizatulaqma \& others, 2019).

- Study entitled: Evaluation of consumer purchasing behaviors in the covid-19 pandemic period in the context of Maslow's Hierarchy of needs.

This study aims to analyze the purchasing behavior of consumers based on Maslow's hierarchy of needs theory, In the study firstly Maslow's theory of needs 
hierarchy is given, then important researches and reports in the world and in turkey during the Covid 19 pandemic were mentioned (Erdal, 2020).

- Study entitled: The Changing grocery shopping behavior of Chinese consumers at the outset of the covid-19 outbreak.

This study aims on the embryonic stage of the covid-19 pandemic in china, this resulted in major disruptions to one of the most common market processes in retail, this study suggests avenues for further scholarly research and policy making related to the impact this behavior may be having around the world on society's more vulnerable groups, particularly the elderly (Junxiong \& others, 2020).

- Study entitled: Coronavirus crisis and its effects on the economy.

This study aims to know the impact of the corona virus on the economy, the current economic turmoil turns to be more severe and lasting being aggravated by the epidemiological uncertainties, including technological shift varying the direction and volume of trade flows adjustments of structural proportions and relative prices (Buklemishev, 2020).

Through a review of these studies that dealt with the subject of our research, we find that they are diverse and inclusive for all aspects of the subject. So that it focused on both variables, however, this study differs from previous studies in that the current study studies the economic and commercial side of the implications of the Covid-19 crisis on consumer behavior and purchasing habits in Algeria, and the extent to which commerce directorates control the good implementation of the phases of crisis management.

Through study questions and previous studies, we can formulate the following hypotheses:

\section{Main hypothesis:}

- There is a statistically significant effect at the level of the 0.05 for the phases of managing Covid 19 crisis by commerce directorates on the behavior of the Algerian consumer.

\section{Sub-hypotheses:}

- There is a statistically significant effect at the level of the 0.05 for the phase of managing Covid 19 crisis by trade directorates on the behavior of the Algerian consumer.

- There is a statistically significant effect at the level of the 0.05 for the preparation and the recognition of the existence phase of Covid 19 crisis by commerce directorates affect the behavior of the Algerian consumer. 
○ There is a statistically significant effect at the level of the 0.05 the containment and settlement phase of Covid 19 crisis by commerce directorates affect the behavior of the Algerian consumer.

○ There is a statistically significant effect at the level of the 0.05 for the benefiting phase of Covid 19 crisis by commerce directorates affect the behavior of the Algerian consumer.

The analytical descriptive approach was used through introducing the study variables from the theoretical point of view represented in each of the crisis management variable and consumer behavior. Whereas for the application side is used for the purpose of data collection, a form was designed and distributed to a sample of customers, in order to treat and test study hypotheses. The SPSS 20 program was used.

\section{THEORETICAL BACKGROUND}

The theoretical side deals with a general Introduction to crisis management and consumer buying behavior, we will address them through the following:

\subsection{Introduction to crisis management}

The crisis is an unusual situation that has a decisive impact on the course of normal affairs, as it is a turning point in unstable situations that can lead to undesirable outcomes if the parties concerned are unwilling or unable to contain them and ward off their dangers (Bieber, 1998, p. 25). So that the reason for its emergence was due to the external environmental factors represented by competitors, prevailing principles and values in addition to the internal environmental factors such as weak material, technological and human capabilities and lack of confidence (Umit \& gungen, 2019, p. 67). It is characterized as a turning point in which the growing need for action increases in emergency circumstances, in which conditions of uncertainty, lack of information, time pressure and the need to make correct decisions prevail. It also helps in the emergence of satisfactory behavioral symptoms such as anxiety, loss of social relations and indifference (Shaizatulaqma \& others, 2019, p. 155).

In particular, we find the Covid 19 crisis, which is a global health crisis that already has a devastating impact on the global economy. It first appeared in China and later spread to Europe, Russia and Asia, and it may spread mainly among animals, but it can develop and infect humans ,as in the case of acute pneumonia (stanciu \& others, 2020, p. 6). The outbreak of this epidemic had a strong impact on 
global financial markets as it led to radical changes in the lifestyle of citizens and the business (Rajagopal, 2020, p. 163).

Crisis management is a distinctive administrative process, as it is exposed to a sudden event and needs quick decisive actions in accordance with the developments of the crisis. Therefore, crisis management has the initiative in leading events, influencing them and directing them according to the requirements of (Apuke $\&$ Tunca, 2019, p. 203). The latter is based on four phases, including the phase of avoiding the crisis, and it means confidentiality, caution and speed in dealing with the situation by avoiding the complexity of the procedures, creating public awareness, effective coordination, good planning and careful diagnosis, in addition to implementing the practical plan and following the developments and reducing risks (Huid, Aimee, \& zharg, 2020, p. 100) The phase of preparation and recognition of the existence of a crisis is the willingness to face the circumstances in which the crisis cannot occur and rely on trust and open understanding in dealing with customers, as we cannot expect to know the form and size of the crisis and the reasons for its occurrence in order to prepare for it so that it is considered a more realistic and powerful tool for its management (Oliver \& others, 2020, p. 3).

Furthermore, the stage of containment and settlement of the crisis by making difficult and quick decisions at this stage to quickly correct the situation. If the crisis occurs and it does not deal with it properly, the directorates may face severe problems and losses such as financial loss, accidents and reputation as they affect the consumer's buying behavior and at this stage also the crisis will not wait and the speed is extremely important by following new effective strategies (Shaizatulaqma $\&$ others, 2019, p. 217). Finally, the phase of benefiting from the crisis. At this stage, crises provide a tremendous amount of experience that has a deep impact in the directorates. It proposes preventive measures and procedures to limit the spread of infection because of its significant impact on sectors of activity such as tourism, transport and agriculture (Roggeveen \& sethurman, 2020, p. 300).

\subsection{Consumer buying behavior}

The consumer's buying behavior is the action which was realized by the individual in the purchase, use, or benefit from of a product or service that includes a number of mental and social processes that lead to the achievement of that (Rajyalakshmi, 2015, p. 40)As it is involved in phases including the consumer decision-making process and identifying the problem and searching for information to solve the problem in addition to identifying products... etc. (Sander le leeuw \& Dullaert, 2018, p. 256). It is one of the most important subjects studied in the 
directorate, it acquires greater significance from one person to another as studies of consumer behavior benefit the individual by providing him with all the information and data that constitute a basic repertoire that helps him in making successful purchasing decisions that satisfy his needs and are compatible with his purchasing capabilities, inclinations and tastes (Bucko, kakalejcik, \& Ferencova, 2018, p. 6).

It also helps the state in drawing up its commercial and regulatory policy to guide the various commercial and economic institutions in defining its pricing and promotional strategies as well as determining the supply and distribution outlets to provide various goods and services. (Chandra \& musumdar, 2018, p. 24), Consumer behavior is characterized by being unstable, changeable at any moment, which makes the possibility of generalizing the study of his behavior limited in limited periods or for some goods and services, and it is also distinguished by being constantly affected by cognitive, psychological and external environment (Bressolles, Senecal, \& Durrieu, 2014, pp. 889-896)

Social and cultural features, such as culture, social class, beliefs and attitudes also influence consumer behavior, as it deals with products, brands, and the type of stores (koyluoglu, 2018, p. 317). As for the effects of the external environment today, due to the global health pandemic Covid-19, it has led to the development of trade and online shopping very quickly, and in a very small time period, due to recommendations to maintain social distance and domestic quarantine, as it is one of the main solutions that limit the spread of the epidemic and the growing uses of technology in the business environment, which in turn leads to economic recovery (Park, 2019, p. 56).

The aim of studying consumer behavior is to enable the state as an organizer of economic and commercial activity, to understand what the consumer makes daily purchasing decisions, and to enable researchers to understand factors or personal influences and external or environmental factors and influences that affect consumer behavior and satisfaction (See Maddox, 1981, p. 54). It also enables economic, commercial and service institutions to know the behavior of current and potential buyers and to find out how to allow them to cope with them and get them to act in a manner consistent with their goals (Tuzzahrah \& others, 2018, p. 53).

Crisis management is also an important topic that plays a major role in influencing consumer behavior, as the primary goal of crisis management is to search and obtain appropriate information for decision-making, and that the primary goal of a study of consumer behavior is to enable it to understand what it makes daily purchasing decisions Which is determined by some internal and external factors as it depends on the effects of marketing variables and emphasizes the external 
influences of consumer trends and behavior through intense competition, this is what made consumers change their purchasing behavior by being a challenge to the behavior and promotes harmful ideas and behaviors in the consumer as crisis management (Ebrahimabad \& mirab, 2018, p. 1068).

\section{The EMPIRICAL STUDY}

In order to test the study hypotheses and arrive at conclusions about the effect the phases of Covid-19 crisis management by the directorates of commerce in Algeria on the consumer behavior, the case of the Algerian consumer was studied during the time period from March 2020 to July 2020, through a random sample.

\subsection{Population and sample of study}

The research community is represented by all Algerian consumers, as the population of Algeria is estimated, according to January 2020 statistics, to be 43 million, $66.60 \%$ of whom are within the age group of the respondents, who are between 15 years of age to 75 (Population Algerienne, 2020), which is equivalent to approximately 28 million people. It is the size of the survey population for this study.

A random sample was selected according to the formula: it is used for these calculations (Morgan, 1970, pp. 607-610):

$$
n=\frac{X^{2} * N^{*} P^{*}(1-P)}{\left(M E^{2 *}(N-1)\right)+\left(X^{2 *} P^{*}(1-P)\right)}
$$

Where:

$\mathrm{n}=$ sample size

$\mathrm{X}^{2}=\mathrm{Chi}-$ square for the specified confidence level at 1 degree of freedom

$\mathrm{N}=$ Population Size

$\mathrm{P}=$ population proportion ( 50 in this table)

$\mathrm{ME}=$ desired Margin of Error (expressed as a proportion)

With the use of the sample size determination table at $95 \%$ confidence, and Margin of Error of 2.5\%, (Advisors, 2020), the sample was estimated at 1537 individuals, and the electronic questionnaire was distributed to them, 1356 analyzable forms were retrieved, means a response rate of $88.22 . \%$

\subsection{Consistency and Stability coefficients}

In order to test the validity of the internal consistency, we used the correlation coefficient for Pearson, and to measure and test the reliability of the questionnaire, we used the Alpha Cronbach coefficient as follows: 
Table 1: Internal consistency

\begin{tabular}{|c|c|c|}
\hline The axes & Correlation coefficient & significance level \\
\hline $\begin{array}{l}\text { The phase of avoiding } \\
\text { the crisis }\end{array}$ & $0,817 * *$ & 0,000 \\
\hline $\begin{array}{l}\text { Preparation and } \\
\text { recognition phase }\end{array}$ & $0,866^{* *}$ & 0,000 \\
\hline $\begin{array}{l}\text { The containment and } \\
\text { settlement phase }\end{array}$ & $0,887 * *$ & 0,000 \\
\hline $\begin{array}{c}\text { The phase of } \\
\text { benefiting from the } \\
\text { crisis }\end{array}$ & $0,868 * *$ & 0,000 \\
\hline consumer's behavior & $0,673 * *$ & 0,000 \\
\hline
\end{tabular}

Source: Own calculations based on the output of the program SPSS

The table shows the correlation coefficients of Pearson between each axis of the study in the total degree, where the correlation coefficients ranged between $(0,673-0,887)$, which is positive and statistically function at a significance level of 0.01 , thus the axes are considered true to what they were designed to measure.

Table 2: Alpha Cronbach coefficient for each axis

\begin{tabular}{ccc}
\hline The axes & Number of terms & $\begin{array}{c}\text { Alpha Cronbach } \\
\text { coefficient }\end{array}$ \\
\hline $\begin{array}{c}\text { The phase of avoiding } \\
\text { the crisis } \\
\text { Preparation and } \\
\text { recognition phase } \\
\text { The containment and } \\
\text { settlement phase }\end{array}$ & 04 & 0,645 \\
$\begin{array}{c}\text { The phase of benefiting } \\
\text { from the crisis } \\
\text { consumer's behavior } \\
\text { All the axes of study }\end{array}$ & 04 & 0,661 \\
\end{tabular}

Source: Own calculations based on the output of the program SPSS

Based on the results obtained This table indicates that the value of the Alpha Cronbach coefficient for the various axes exceeded 60\%, which ranges between 0.645 and 0,897, which is a high value, while the total value of the Alpha Cronbach coefficient is 0.921 , which is also a high value, and this indicates the stability of the measuring instrument from The area of the statements included in the questionnaire. 


\subsection{Normal distribution test}

The Kolmogorov-Smirnov test was used to find out whether the study model was subject to a normal or free distribution, with the purpose of determining the nature of the tests used in the hypothesis test. The results were as follows:

Table 3: The normal distribution of the study axes

\begin{tabular}{ccc}
\hline \multicolumn{3}{c}{ Kolmogorov-smirnov } \\
\hline Axes & Value Z & Sig* \\
All axes of the study & 1,94 & 0,001 \\
$*$ The distribution is normal if the significance level is $>0.05$ & \\
\hline
\end{tabular}

Source: Own calculations based on the output of the program SPSS

Through looking at the table and at the level of significance (0.05), it is clear that all axes do not follow the normal distribution, as the rates of the natural distribution of all axes were smaller than (0.05), which is the method adopted in the statistical treatment of this study, ultimately, it is not possible to perform parameter tests on it. This is what requires relying on nonparametric tests to answer the established hypotheses

\subsection{Descriptive Statistics of axes}

According to the outputs of the SPSS program, by calculating the arithmetic average and standard deviation of the various questionnaire statements in order to analyze the respondents' answers, the results are shown in the following table according to each axis of the study:

Table 4: Descriptive Statistics of axes

\begin{tabular}{cccc}
\hline Axes & $\begin{array}{c}\text { The } \\
\text { arithmetic } \\
\text { mean }\end{array}$ & $\begin{array}{c}\text { standard } \\
\text { deviation }\end{array}$ & Arrangement \\
\hline $\begin{array}{c}\text { Crisis prevention } \\
\text { preparation and } \\
\text { recognition }\end{array}$ & 2,8258 & 0,81923 & average \\
$\begin{array}{c}\text { Containment and } \\
\text { settlement }\end{array}$ & 3,0916 & 0,80080 & average \\
$\begin{array}{c}\text { Take advantage of the } \\
\text { crisis }\end{array}$ & 3,3496 & 0,75959 & average \\
consumer's behavior & 3,2334 & 0,87619 & average \\
\hline
\end{tabular}

Source: Own calculations based on the output of the program spss 
Table 4 indicates the study sample answers about the expressions related to the level of importance of the phases of Covid-19 crisis management and consumer behavior, which came as follows:

- the arithmetic mean of Crisis prevention, is estimated at 2,8258 and a standard deviation of 0,81923 , and this shows an average degree of approval on the part of the study sample, which indicates that the Trade Directorate did not care well about the crisis avoidance phase.

- the arithmetic mean for preparation and recognition, is 3,0916 and a deviation of 0,80080 , and this indicates an average degree of approval by members of the study sample, which indicates that the Directorate of Commerce did not take care well of the preparation and recognition stage of a crisis.

- the arithmetic mean for Containment and settlement, is estimated at 3,3496 and a deviation of 0.75959 , and this shows an average degree of approval by the members of the study sample, which indicates that the Directorate of Trade did not take a good attention in the stage of containing and settling the crisis.

- the arithmetic mean for Take advantage of the crisis, is estimated at 3,2334 and a deviation of 0,87619 , and this shows an average degree of approval by the members of the study sample, which indicates that the Directorate of Commerce did not care about the stage of benefiting from the crisis.

- the arithmetic mean of consumer's behavior, is estimated at 3,3072 and the deviation is 0.62109 , and this shows an average degree of approval on the part of the study sample, which indicates that the Trade Directorate did not take good care of consumer behavior.

\subsection{Testing Study Hypotheses}

To test the hypothesis of study, the anova T-test was used, the results of which in the following table:

The first hypothesis: There is a statistically significant effect at the 0.05 level of significance for the stage of avoiding the Covid 19 crisis by the Commerce Directorate on the Algerian consumer behavior.

Table 5: The result of a simple regression analysis to test the effect of the Covid-19 crisis avoidance phase by the Trade Directorate on Algerian consumer behavior

\begin{tabular}{ccccccc}
\hline Axis & $\begin{array}{c}\text { B } \\
\text { value }\end{array}$ & T value & F value & $\mathbf{R}$ & $\mathbf{R}^{\mathbf{2}}$ & Sig \\
\hline $\begin{array}{c}\text { The first } \\
\text { hypothesis }\end{array}$ & 0,350 & 19,125 & 365,775 & 0,461 & 0,213 & 0,000 \\
\hline
\end{tabular}

Source: Own calculations based on the output of the program SPSS 
Table 5 shows the impact of the phase of avoiding the Covid 19 crisis by Commerce directorates on the behavior of the Algerian consumer.the correlation coefficient reached $(0.461)$ at the level of significance of 0,000 less than 0.05 and the determination coefficient $(0,213)$, means its value $(21,3 \%)$ of changes in the level of Algerian consumer behavior resulting from the change in the level of importance of the phase of avoiding the Covid 19 crisis, The value of the impact degree was (0.350),this reflects that the increase in the phase of avoiding the Covid 19 crisis leads to an increase in the level of Algerian consumer behavior, which shows the significance of this relationship is the value of $F(365,775)$ and the value of $T$ $(19,125)$, This confirms the validity of the first sub-hypothesis, which says: There is a statistically significant effect at the 0.05 level of significance for the stage of avoiding the Covid 19 crisis by the Commerce directorates on the behavior of the Algerian consumer.

The second hypothesis: There is a statistically significant effect at the 0.05 level of significance of the preparation stage and the recognition of the existence of the Covid 19 crisis by the directorates of commerce on the behavior of the Algerian consumer.

Table 6: The result of the simple regression analysis to test the effect of the preparation stage and the recognition of the presence of Covid 19 by trade directorates on the behavior of the Algerian consumer.

\begin{tabular}{ccccccc}
\hline Axis & $\begin{array}{c}\text { B } \\
\text { value }\end{array}$ & $\begin{array}{c}\text { T } \\
\text { value }\end{array}$ & F value & R & $\mathbf{R}^{\mathbf{2}}$ & Sig \\
\hline $\begin{array}{c}\text { The } \\
\text { second } \\
\text { hypothesis }\end{array}$ & 0,386 & 21,134 & 446,649 & 0,498 & 0,248 & 0,000 \\
\hline
\end{tabular}

Source: Own calculations based on the output of the program spss

Table No. 6 shows the effect of the preparation and the recognition phase of the existence of Covid 19 crisis by the trade directorates on the behavior of the Algerian consumer, as the results showed the presence of the effect of the preparation and the recognition phase of the existence of Covid 19 crisis on the behavior of the Algerian consumer. the correlation coefficient reached $(0,498)$ at the level of significance of 0,000 less than 0.05 and the determination coefficient $(0,248)$, means its value $(24,8 \%)$ of changes in the level of Algerian consumer behavior resulting from the change in the level of importance of the preparation and the recognition phase of the existence of the Covid 19 crisis. The value of the effect degree was (0.386), and this reflects that the increase in the stage of avoiding the Covid 19 crisis leads to an increase in the level of the Algerian consumer behavior, and what shows the significance of this relationship is the value of $F(446,649)$ and the value of $T$ 
$(21,134)$, This confirms the validity of the first sub-hypothesis, which says: There is a statistically significant effect at the 0.05 level of significance for the preparation and the recognition phase of the existence of the Covid 19 crisis by trade directorates on the behavior of the Algerian consumer.

The third hypothesis: There is a statistically significant effect at the 0.05 level of significance of the stage of containment and settlement of the Covid 19 crisis by the directorates of Commerce on the behavior of the Algerian consumer.

Table 7: The result of a simple regression analysis to test the effect of the containment and settlement of the Covid 19 crisis by the directorates of

Commerce on the behavior of the Algerian consumer

\begin{tabular}{ccccccc}
\hline Axis & $\begin{array}{c}\text { B } \\
\text { value }\end{array}$ & $\begin{array}{c}\text { T } \\
\text { value }\end{array}$ & F value & R & $\mathbf{R}^{2}$ & Sig \\
\hline $\begin{array}{c}\text { The third } \\
\text { hypothesis }\end{array}$ & 0,456 & 24,744 & 612,290 & 0,558 & 0,311 & 0,000 \\
\hline
\end{tabular}

Source: Own calculations based on the output of the program SPSS

Table No. 7 shows the effect of the phase of containing and settling the Covid 19 crisis by the Commerce directorates on the behavior of the Algerian consumer, as the results showed the presence of the effect of the phase of containment and settlement of the Covid 19 crisis on the behavior of the Algerian consumer,the correlation coefficient reached $(0,5588)$ at a significance level of 0,000 less than 0,05 and the determination coefficient $(0,311)$, means its value of $(31,1 \%)$ of changes in the level of Algerian consumer behavior resulting from the change in the level of importance of the stage of containment and settlement of the Covid 19 crisis. The value of the degree of effect was (0.456), this reflects that the increase in the phase of containment and settlement of Covid 19 leads to an increase in the level of Algerian consumer behavior, which shows the significance of this relationship is the value of $\mathrm{F}(612,290)$ and the value of $\mathrm{T}(24,744)$, This confirms the validity of the first sub-hypothesis, which says: There is a statistically significant effect at the 0.05 level of significance for the containment and settlement of the Covid 19 crisis by the Commerce directorates on the behavior of the Algerian consumer.

The fourth hypothesis: There is a statistically significant effect at the 0.05 level of significance for the stage of benefiting from the Covid 19 crisis by the directorates of commerce on the behavior of the Algerian consumer. 
Table 8: The result of a simple regression analysis to test the effect of the benefit stage of the Covid 19 crisis by the Commerce Directorate on the Algerian consumer behavior

\begin{tabular}{ccccccc}
\hline Axis & $\begin{array}{c}\text { B } \\
\text { value }\end{array}$ & $\begin{array}{c}\text { T } \\
\text { value }\end{array}$ & F value & R & $\mathbf{R}^{\mathbf{2}}$ & Sig \\
\hline $\begin{array}{c}\text { The fourth } \\
\text { hypothesis }\end{array}$ & 0,276 & 15,573 & 242,509 & 0,390 & 0,152 & 0,000 \\
\hline
\end{tabular}

Source: Own calculations based on the output of the program SPSS

Table No. 8 shows the effect of the phase of benefiting from the Covid 19 crisis by the Commerce directorates on the behavior of the Algerian consumer, as the results showed the presence of the effect of the phase of benefiting from the Covid 19 crisis on the behavior of the Algerian consumer, as the correlation coefficient reached (0.390) at a significance level of 0,000 less than 0.05 and the determination coefficient $(0,152)$ means its value $(15.2 \%)$ of changes in the level of Algerian consumer behavior resulting from the change in the level of importance of the stage of benefiting from the Covid 19 crisis. The value of the degree of effect was (0.276), and this indicates that the increase in the phase of benefiting from the Covid 19 crisis leads to an increase in the level of Algerian consumer behavior, which shows the significance of this relationship is the value of $F(242,509)$ and the value of $\mathrm{T}(15,573)$, this confirms the validity of the first sub-hypothesis, which says: There is a statistically significant effect at the level of significance 0,05 for the stage of benefiting from the Covid 19 crisis by the trade directorates on the behavior of the Algerian consumer.

Fifth hypothesis: There are statistically significant differences at the level of 0.05 in the answers of the sample members regarding the impact of crisis management on the behavior of the Algerian consumer due to personality variables.

Table 9: Mann-Whitney and Kruskal Wallis test for the significance of the differences in the respondents 'attitudes about the impact of managing the Covid 19 crisis by

Commerce directorates on the Algerian consumer behavior due to personal variables

\begin{tabular}{|c|c|c|c|c|}
\hline \multirow{5}{*}{ sample } & \multicolumn{2}{|c|}{ variable } & U de Mann- & Sig \\
\hline & $\begin{array}{c}\text { male } \\
\text { female }\end{array}$ & Gender & 139852 & 0,000 \\
\hline & \multicolumn{2}{|c|}{ variable } & Khi-deux & sig \\
\hline & $\begin{array}{l}\text { year } 15-35 \\
\text { year } 35-55 \\
\text { year } 55-75\end{array}$ & age & 3,942 & 0,139 \\
\hline & $\begin{array}{c}\text { Without income } \\
45000-15000 \\
75000-45000\end{array}$ & salary & 5,910 & 0,206 \\
\hline
\end{tabular}




$\begin{array}{cccc}\begin{array}{c}95000-75000 \\ 95000 \text { and more } \\ \text { secondary } \\ \text { university }\end{array} & \begin{array}{c}\text { Educational } \\ \text { level }\end{array} & 4,731 & 0,094 \\ \text { postgraduate } & & \\ \text { internet } & \begin{array}{c}\text { The source of } \\ \text { television }\end{array} & 2,631 & 0,452 \\ \text { receiving the } & & \\ \text { acquaintances } & \text { information } & & \\ \text { All previous means } & & & \end{array}$

Source: Own calculations based on the output of the program spss

Through the above table, we notice that the level of significance for the means of the respondents' ranks in relation to the variables of age and educational level, income and the source of receiving information is not statistically significant because it is bigger than the level of significance approved in the study (0.05), Consequently, there are no statistically significant differences in the respondents' answers about the effect of managing the Covid 19 crisis by the Commerce directorates on the behavior of the Algerian consumer due to variables of age, income, educational level and source of information. However, we notice that the level of significance for the mean of the respondents' ranks for the variable of gender was estimated at 0,000 , thus it is statistically significant at the level of significance 0.05 , therefore we accept the first hypothesis, which states that there are statistically significant differences in the respondents 'answers due to the gender variable.

Main hypothesis: There is a statistically significant effect at the 0.05 level of significance for the phases of managing the Covid 19 crisis by the Commerce Directorate on the behavior of the Algerian consumer.

Table 10: The result of a multiple regression analysis to test the effect of the stages of Covid-19 crisis management by the Commerce Directorate on the Algerian consumer behavior

\begin{tabular}{ccccc}
\hline axis & $\mathbf{R}$ & $\mathbf{R}^{\mathbf{2}}$ & F value & sig \\
\hline $\begin{array}{c}\text { main } \\
\text { hypothesis }\end{array}$ & 0,726 & 0,527 & 376,055 & 0,000 \\
\hline
\end{tabular}

Source: Own calculations based on the output of the program SPSS

Table No. 10 shows the effect of the stages of managing the Covid 19 crisis by the Commerce Directorate on the behavior of the Algerian consumer. We notice that there is an effect of the phases of managing the Covid 19 crisis on the behavior of the Algerian consumer, as the correlation coefficient reached (0.726) at a level of 
significance of 0,000 less than 0.05 , while the determination coefficient reached (0.527), means its value $(52.7 \%)$ of changes in the level of Algerian consumer behavior resulting from the change in the level of control of the phases of managing the Covid crisis 19. The significance of this effect confirms the value of $F(376,055)$, which is a function at a level less than 0.05 , and this confirms the validity of the main sub-hypothesis, which says: There is a statistically significant effect at the level of 0.05 significance for the phases of Covid-19 crisis management by the directorates of commerce in Algeria on the consumer behavior.

\section{Conclusion}

In this study we demonstrated the importance of crisis management according to its various phases and its effect on consumer behavior, which is followed by the various directorates of Commerce in Algeria, as it is a distinct and complex administrative process. Because it is exposed to a sudden event and needs rapid decisive actions consistent with the developments of the Covid-19 crisis, and this was from the first phases of crisis management until controlling it and restoring the nature of a sound commercial activity. And the extent of its contribution to organizing and planning processes for managing crises effectively and professionally, and accordingly, the following conclusions can be drawn:

The Directorates of commerce was not fully aware of the seriousness of the crisis Covid 19.Furthermore, it has taken all preventive measures to avoid falling into this crisis but on average.It also made early warning before the crisis occurred, but not in a good way. In addition to this, it did not plan tightly to provide all the needs of the consumer before Falling into crisis.Besides that, the Directorates of Commerce has not laid down completely clear instructions for commercial activity specifying how to deal with the crisis. Moreover, it did not handle well effectively and efficiently with the crisis once it occurred. And then, it worked to cooperate with the relevant ministries to solve the crisis (Health and Interior) But not so well. Next, it did not work well to avoid all obstacles during the crisis (speculation and monopoly, scarcity of consumer and medical supplies). Apart from that, it did not deal with this crisis in a manner consistent with its serious nature. Further, it did not work well to prevent the occurrence of Subcrises that may result from the Covid 19 crisis. What is more, the Directorates of Commerce did not perform the required efforts well which is represented in the control, distribution and regulation of commercial work to help contain the effects of the Covid 19 crisis.Another conclusion is that the Directorates of Commerce did not do well to control the factors Causing scarcity of consumables and preventive medical materials in a short period of time. And It did not take appropriate decisions to contain 
the negative effects The resulting from this crisis in time.Also, it did not take appropriate decisions to contain the effects The negative resulting from this crisis in time.And, It is working to improve crisis management programs and plans.Finally, it has gained experience from facing this crisis that will take advantage of it to face of potential crises but not properly.

In other part, the decisions taken by the Directorates were not improved well over time to face this crisis. As, this crisis affected the daily consumer behavior. It also made the consumer more cautious in making purchase decisions. Furthermore, it made the consumer more cautious in making purchase decisions. Moreover, it made the consumer to switch from buying luxury to necessary goods. Besides that, the consumer purchases durable and avoids perishable products. Ultimately, the crisis made the consumer to switch from purchasing expensive to consumer goods and preventive and health products.

Concerning the conclusions about the consumer are as follows: the consumer is buying in medium quantities, to reduce the number of shopping times, furthermore, he buys local products and avoids buying imported products but not properly. Also, he is helped by social media to make a purchase decision but not well and properly. Another conclusion is that the consumer is taking precautions and preparing for storage and supply, but not properly. Then, the websites and social media did not provide well for the consumer All the information about the products he's looking for. The consumer uses the Internet and social media, in a moderate degree, in order to search for the products and services he needs. Finally, he will continue to carry out the electronic purchase process until the end of the crisis, but not significantly.

\subsection{Results}

The study found that there is little interest by commerce directorates in the phases of crisis management; this is what differs from the study of (stanciu \& others, 2020) and (Erdal, 2020). The results also showed that there are different effects of the phases of crisis management by the commerce directorates in Algeria on consumer behavior. The most important is the weak effect of the crisis benefiting phase on consumer behavior this is by $15.2 \%$, and a weak impact of the crisis settlement and containment phase on consumer behavior, at a rate of $31.1 \%$, the study also found that there is a weak effect of the crisis avoidance phase on consumer behavior, with a rate of $21.3 \%$, in addition, there is also a weak effect of the preparation stage and the recognition of the existence of a crisis on the behavior of the Algerian consumer, at a rate of $24.8 \%$, this is in agreement with the study of (Buklemishev, 2020), and (Shaizatulaqma \& others, 2019). the study found a strong 
positive effect and relationship between the management of the Covid 19 crisis and the behavior of the Algerian consumer at a significance level of 0.05 of $72.6 \%$, and this is in agreement with the study of (Junxiong \& others, 2020), the results also showed that there are no statistically significant differences on the effect of Covid 19 crisis management on Algerian consumer behavior according to age and income, educational level and the source of information received, and the presence of statistically significant differences about the effect of Covid 19 crisis management on the behavior of the Algerian consumer according to gender.

\subsection{Recommendations}

Through previous results, a set of recommendations will be formulated regarding the Covid 19 crisis and its effect on the Algerian consumer behavior, the most important of them are:

- The necessity for the directorates of Commerce to pay attention to managing the crisis, Because of its great importance in influencing the behavior of the Algerian consumer.

- The necessity for the directorates of Commerce to pay attention to the preparation stage and to acknowledge the existence of the crisis, To avoid all obstacles when they occur.

- The necessity for the directorates of Commerce to pay attention to the stage of settling and containing the crisis, to prevent sub-crises that may result from the Covid-19 crisis.

- The necessity for the directorates of Commerce to pay attention to the phase of benefiting from the crisis, In order to gain experience from facing this crisis, which will benefit them to face potential crises in the future.

- Prior strategic plans must be made on which commerce directorates rely to face crises and get out of them with the least possible damage.

- The necessity to learn and take lessons learned from the Covid 19 crisis, in order to obtain field experience in crisis management.

- Directorates of Commerce are keen to carry out all preventive measures to avoid falling into crises.

- Developing a flexible plan in order to respond to consumer requirements during future crises that trade directorates cannot limit, but rather can avoid.

- Attention should be given to complaints made by consumers.

- Working on consumer awareness and education of the concept of crisis management and its phases. 


\section{REFERENCES}

1. Population Algerienne. (2020, 01 30). Retrieved 06 20, 2020, from https://www.populationpyramid.net/ar/2020

2. Advisors, T. R. (2020, 06 15). Sample Size Table. Retrieved 06 29, 2020, from https://www.research-advisors.com/tools/SampleSize.htm

3. Apuke, O. D., \& Tunca, E. (2019, January ). Social Media and crisis management. A review and Analysis of existing studies.

4. Bieber, R. (1998). clutch management in crisis. RIS management journal, Vol 35.

5. Bressolles, Senecal, \& Durrieu, F. (2014). A consumer typology based on e-service quality and e-satisfaction. journal of relaiting and consumer services.

6. Bucko, J., kakalejcik, L., \& Ferencova, M. (2018). Online shopping: factors that affect consumer purchasing behavior cogent OA. journal cogent business \& management, http:// doi.org/10.1080/23311975.

7. Buklemishev, O. V. (2020). Coronavirus crisis and its effects on the economy, Population and economics, https://doi.org/10.3897/ popecon.4e53295.

8. Chandra, S., \& musumdar, S. (2018). Impact of sales promotional tools on the consumers buying behavior: study related with apparel relaiting business. International journal of Applied research.

9. Ebrahimabad, M., \& mirab, v. (2018). Effective factors on consumer buying behavior in group buying, Revista publicando.

10. Erdal, s. (2020, june). Evaluation of consumer purchasing behaviors in the covid-19 pandemic period in the context of Maslow's Hierarchy of needs.

11. Huid, H. j., Aimee, k., \& zharg, y. (2020). cautiously optimistic: Chinese consumer behaviour post-covid 19, Mckinsey \& company, (online).

12. Junxiong, L., \& others. (2020). The Changing grocery shopping behavior of Chinese consumers at the outset of the covid-19 outbreak, Tijdshrif voor Economische en Sociale geographies. research note.

13. Koyluoglu, S. (2018). A Reasearch on consumer behavior : konya sample. Article Selcuk university.

14. Morgan, K. (1970). Determining Sample Size for Research Activities. Educational and Psychological Measurement.

15. Oliver, T., \& others. (2020). Global crisis and role of bise, Bus Inf Eng, https:// doi.org/10.1007/s12599-020-00657-w.

16. Park, H. (2019). Digital innovation Adoption and its economic impact focused on path analysis at national level. journal of open innovation : technologie, market, and complexity5(3), https:// doi.org/10.3390/ joitmc 5030056.

17. Rajagopal, D. (2020). Development of consumer behavior, In Transgenerational marketing, springer international publishing.

18. Rajyalakshmi, N. (2015). Factors influencing online shopping behavior of urban consumers in India. international journal of online marketing, vol5, Issue 1. 
19. Roggeveen, L., \& sethurman, R. (2020). How the covid pandemic may change the world of relaiting. journal of relaiting, https:// doi: 10.1016/ j.jretari 2020.04.002.

20. Sander le leeuw, D. H., \& Dullaert, w. E. (2018). consumer behavior and order fulfillment in online retailing. international journal of management reviews ( vol 20), https://doi:10.1111/ijmr.12129.

21. See Maddox, R. (1981). two-factor theory and consumer satisfaction : replication and Extension pune. journal of consumer research.

22. Shaizatulaqma, K. A., \& others. (2019). The influence of crisis management on customer purchase intention, International conference on business sustainability and innovation. The European proceedings of social \& behavioral science, https:// doi.org/10.154.

23. Stanciu, S., \& others. (2020). consumers behavior in crisis situations. Research on the effects of covid-19 in Romania. Annals of dunarea de jos, https://doi.org/10.35219/eai 1584040975.

24. Tuzzahrah, Z., \& others. (2018). Impulsive and complulsive buying in retail business: an overview of consumer behavior in Indounisia, Rjoas, è(79), https:// doi.org/10.18551/ rjoas.

25. Umit, A., \& gungen, A. R. (2019). the Making of Turkey's 2018-2019 Economic Crisis. Institute for International Political Economy Berlin. 